\title{
Kernos
}

Revue internationale et pluridisciplinaire de religion grecque antique

6 | 1993

Varia

\section{Revue des rééditions, réimpressions et traductions}

\section{(2) OpenEdition \\ Journals}

Édition électronique

URL : http://journals.openedition.org/kernos/576

DOI : 10.4000/kernos.576

ISSN : 2034-7871

Éditeur

Centre international d'étude de la religion grecque antique

Édition imprimée

Date de publication : 1 janvier 1993

Pagination : 400-401

ISSN : 0776-3824

\section{Référence électronique}

"Revue des rééditions, réimpressions et traductions », Kernos [En ligne], 6| 1993, mis en ligne le 07 avril 2011, consulté le 24 septembre 2020. URL : http://journals.openedition.org/kernos/576 ; DOI : https://doi.org/10.4000/kernos.576 
-, Donna e simboli femminili nella gnosi del II secolo, in La donna nel pensiero antico, Genova, Marietti, 1992, p. 305-329.

Florence DoYEN, R. PREYs, La présence grecque en Égypte ptolémalque, les traces d'une rencontre, in M. BROzE, Ph. TALON (éds), L'atelier de l'orfêvre. Mélanges offerts à Ph. Derchain, Leuven, Peeters, 1992 (Coll. de l'IPHO «Lettres orientales», 1), p. 63-85.

René LeBrun, De quelques cultes lyciens et pamphyliens, in Hittite and other Anatolian and Near Eastern Studies in Honor of Sedat Alp, Ankara, 1992, p. 357-363.

J. Redfield, From Sex to Politics: The Rites of Artemis Triklaria and Dionysos Aisymnetes at Patras, in D.M. HALPERIN, J.J. WinkLER, F.I. ZEITLIN (éds), Before Sexuality: The Construction of Erotic Experience in the Ancient Greek World, Princeton Univ. Press, 1990, p. 115-134.

Maria RocCHI, Les oracles des Pisistratides dans le temple d'Athéna, in C. BAURAIN, C. Bonnet, V. KRINGS (éds), Phoinikeia grammata. Lire et écrire en Méditerranée. Actes du Colloque de Liège, 15-18 novembre 1989, Namur, Société des études classiques, 1991 (Studia Phoenicia - Coll. d'études classiques, 6), p. 577-589.

P. Roesch, Les cultes égyptiens en Béotie, in L. Criscuolo, G. GeraCi, Egitto e Storia dall'Ellenismo all'Età Araba. Bilancio di un confronto, Bologna, 1989, p. 621-629.

Suzanne SAÏD, Le mythe de l'Aréopage avant la Constitution d'Athènes, in Aristote et Athènes. Fribourg (Suisse), 23-25 mai 1991, études rassemblées par M. PiÉrart, Paris, de Boccard, 1993, p. 155-184

K. Tzavélla-Evjen, Heroes who do not "Rest in Peace": Legends and the Archaeological Record, in J.M. FossEY, J. MoRIN (éds), Boeotia Antiqua II. Papers on recent work in Boiotian Archaeology and Epigraphy, Amsterdam, Gieben, 1992 (McGill Univ. Monographs in Classical Archaeology and History, 11)

A. VENERI, Posidone e l'Elicone: alcune osservazioni sull'antichità e la continuità di una tradizione mitica beotica, in A. SCHACHTER (éd.), Essays in the topography, history and culture of Boiotia, Montréal, 1990 (Teiresias Supplement, 3), p. 129134.

K.-W. WELWEI, Heroenkult und Gefallenenehrung im antiken Griechenland, in G. BINDER, B. EFFE (éds), Tod und Jenseits im Altertum, Trier, Wissenschaftlicher Verlag Trier, 1991, p. 50-70.

\section{Rééditions, réimpressions et traductions}

Bruit Z aidman Louise, Schmitt Pantel Pauline, Religion in the Ancient Greek City, transl. by Paul Cartledge, Cambridge Univ. Press, $1992, \mathrm{xX}+278$ p. ISBN : 0-521-42357-0.

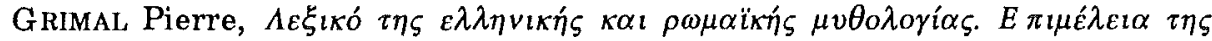

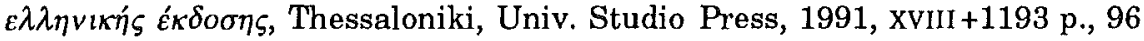
fig. [éd. or. 1976, P.U.F.]. 
LoRAUX Nicole, Tragic Ways of Killing a Woman, transl. by Anthony Forster, Harvard Univ. Press, 1991, XI+100 p. [paperback 1987].

PARKE Herbert W., Sibyls and Sibylline Prophecy in Classical Antiquity, ed. by B.C. MCGrNG, London, Routledge, 1992, IX+237 p. [paperback 1988].

Vernant Jean-Pierre, Mortals and immortals. Collected essays, ed. by Froma I. ZeITLIN, Princeton Univ. Press, 1991, IX+341 p.

\section{Ouvrages reçus à la rédaction}

AA.VV., Problèmes de la morale antique. Sept études, réunies par Paul DEMONT, Université d'Amiens, Faculté des Lettres, Centre de Recherches sur l'Antiquité grecque et latine, 1993, 131 p. ISBN : 2-9505744-1-6.

Aristote et Athènes. Aristoteles and Athens. Fribourg (Suisse), 23-25 mai 1991, études rassemblées par Marcel PIÉRART, Paris, de Boccard, 1993, viii + 341 p. ISBN : 2-7018-0073-0.

AUBRIOT Danièle, Prière et conceptions religieuses en Grèce ancienne jusqu'à la fin du Ve siècle av. J.-C., Paris, de Boccard, 1992, 604 p. (Coll. de la Maison de l'Orient Méditerranéen, 22. Série littéraire et philosophique, 5). ISBN : 2 903264-14-7.

Avagianou Aphrodite, Sacred Marriage in the Rituals of Greek Religion, Bern, Frankfurt/M., Lang, 260 p. (European Univ. Studies. Series 15, Classics, 54). ISBN : 3-261-04432-2.

BeAtrice Pier Franco, L'eredità delle origini. Saggi sul cristianesimo primitivo, Genova, Marietti, 1992, 298 p. ("Dabar". Studi biblici e giudaistici). ISBN : 88211-6808-5.

BoDÉüs Richard, Aristote et la théologie des vivants immortels, Québec-Paris, Bellarmin-Les Belles Lettres, 1192, 396 p. (Coll. "Noésis"). ISBN : 2-89007-7225.

BoNNET Corinne, JoURDAIN-ANNEQUIN Colette (éds), Héraclès. D'une rive à l'autre de la Méditerranée. Bilan et perspectives. Actes de la Table Ronde, Academia Belgica - École française de Rome, 15-16 septembre 1989 à l'occasion du Cinquantenaire de l'Academia Belgica, en Hommage à Franz Cumont, son premier Président, Bruxelles-Rome, 1992, 361 p., ill. (Etudes de philologie, d'archéologie et d'histoire anciennes publiées par l'Institut historique belge de Rome, 28). ISBN : 90-74461-01-8.

BYL Simon, Les dix dernières années (1983-1992) de la recherche hippocratique, in Lettre d'information $\mathrm{n}^{\circ} 22$ (mai 1993), Université Jean Monnet - Saint Étienne (Centre Jean-Palerne), Université Lumière Lyon II (GDR 0734) (Maison de l'Orient Méditerranéen), $44 \mathrm{p}$.

CANFoRa Luciano, La Bibliothèque d'Alexandrie et l'histoire des textes, Université de Liège, CEDOPAL, 1992, 69 p., ill.

Couloubaritsis Lambros, Aux origines de la philosophie européenne. De la pensée archaïque au néoplatonisme, Bruxelles, De Boeck-Wesmael, 1992, 673 p., ISBN : 2-8041-1571-2. 